\title{
Abnormal functional and morphological regulation of the gastric mucosa in histamine $\mathrm{H} 2$ receptor-deficient mice
}

\author{
Takashi Kobayashi, ${ }^{1}$ Shunsuke Tonai, ${ }^{2}$ Yasunobu Ishihara, ${ }^{3}$ Ritsuko Koga, ${ }^{1}$ \\ Susumu Okabe, ${ }^{2}$ and Takeshi Watanabe ${ }^{1}$ \\ ${ }^{1}$ Department of Molecular Immunology, Medical Institute of Bioregulation, Kyushu University, Fukuoka, Japan \\ ${ }^{2}$ Department of Applied Pharmacology, Kyoto Pharmaceutical University, Kyoto, Japan \\ ${ }^{3}$ Developmental Research Laboratories, Shionogi \& Co., Osaka, Japan \\ Address correspondence to: Takeshi Watanabe, Medical Institute of Bioregulation, Kyushu University, \\ 3-1-1 Maidashi, Higashi-ku, Fukuoka 812-8582, Japan. Phone: 81-92-642-6835; Fax: 81-92-632-1499; \\ E-mail: watanabe@bioreg.kyushu-u.ac.jp. \\ Received for publication January 25, 2000, and accepted in revised form May 2, 2000.
}

To clarify the physiological roles of histamine $\mathrm{H} 2$ receptor (H2R), we have generated histamine H2Rdeficient mice by gene targeting. Homozygous mutant mice were viable and fertile without apparent abnormalities and, unexpectedly, showed normal basal gastric $\mathrm{pH}$. However, the H2R-deficient mice exhibited a marked hypertrophy with enlarged folds in gastric mucosa and an elevated serum gastrin level. Immunohistochemical analysis revealed increased numbers of parietal and enterochromaffin-like (ECL) cells. Despite this hypertrophy, parietal cells in mutant mice were significantly smaller than in wild-type mice and contained enlarged secretory canaliculi with a lower density of microvilli and few typical tubulovesicles in the narrow cytoplasm. Induction of gastric acid secretion by histamine or gastrin was completely abolished in the mutant mice, but carbachol still induced acid secretion. The present study clearly demonstrates that H2R-mediated signal(s) are required for cellular homeostasis of the gastric mucosa and normally formed secretory membranes in parietal cells. Moreover, impaired acid secretion due to the absence of H2R could be overcome by the signals from cholinergic receptors.

J. Clin. Invest. 105:1741-1749 (2000).

\section{Introduction}

The oxyntic mucosa is composed of numerous blind tubular units containing various cell types (1). Each unit is divided into four regions: (a) the pit region containing surface mucous cells, (b) the isthmus containing stem cells, (c) the neck region containing mucous neck cells, and (d) the basal region containing chief cells and enterochromaffin-like (ECL) cells. Acid-producing cells, namely parietal cells, are scattered in the four regions. It has been well-known that parietal cells secrete gastric acid from $\mathrm{H}^{+}, \mathrm{K}^{+}$-ATPase (gastric proton pump) expressed on their secretory membrane upon stimulation with gastrin, acetylcholine (ACh), and histamine through gastrin/cholecystokinin-B receptor (CCK-BR), muscarinic receptors (M1R and M3R), and histamine $\mathrm{H} 2$ receptor $(\mathrm{H} 2 \mathrm{R})$, respectively (2). The physiological significance of histamine signaling mediated by $\mathrm{H} 2 \mathrm{R}$ in gastric acid secretion has been demonstrated by pharmacological studies using selective antagonists such as cimetidine, ranitidine, and famotidine, which have a potent inhibitory effect on secretory response (3). In fact, these antagonists have been used clinically for treatment of peptic ulcer $(4,5)$. By contrast, the acid secretion induced by ACh and gastrin is believed to involve two pathways: either directly by activating the parietal cells or indirectly by stimulating ECL cells that produce and release hista- mine, thus activating parietal cells in a paracrine fashion (2). The relative importance of these two modes of action remains to be clarified.

The intracellular signals in parietal cells transduced from $\mathrm{H} 2 \mathrm{R}$, muscarinic M3 receptor (M3R), and CCK$\mathrm{BR}$ have been investigated (2). Activated H2R increases intracellular cAMP, whereas both M3R and CCK-BR increase intracellular $\mathrm{Ca}^{2+}$ upon binding of their ligands. Synergistic effects on acid secretion have been observed between histamine and gastrin and between histamine and $\mathrm{ACh}(6,7)$. This synergism was thought to reflect interaction between two distinct second messengers in signal transduction pathways $(8,9)$.

Parietal cells have unique structural properties to produce and secrete gastric acid (10). They are relatively large cells containing numerous mitochondria in their cytoplasm. The plasma membrane invaginates deep into the cytoplasm to form an interconnecting system of tortuous channels, termed secretory canaliculi, that are lined by numerous microvilli. Parietal cells contain intracellular vesicles, termed tubulovesicles, in the cytoplasmic region close to the canaliculi. In the resting state, $\mathrm{H}^{+}, \mathrm{K}^{+}$ATPase is stored within cytoplasmic tubulovesicles. Upon stimulation, the tubulovesicles fuse with the apical membrane to form the extended secretory canaliculus, and then functional pumps are recruited to the surface of canaliculus (2). The cessation of acid secretion is 
executed by means of endocytotic internalization of the $\mathrm{H}^{+}, \mathrm{K}^{+}$-ATPase and regeneration of the tubulovesicles. These events must be regulated by signal(s) from cAMP and/or $\mathrm{Ca}^{2+}$-dependant pathways; however, there is little information on the mechanisms responsible for this regulated endocytosis and exocytosis. A recent study revealed that a tyrosine-based motif in the $\beta$ subunit of $\mathrm{H}^{+}, \mathrm{K}^{+}$-ATPase is essential for reinternalization of $\mathrm{H}^{+}, \mathrm{K}^{+}$ATPase. Transgenic mice carrying a mutant $\beta$ subunit developed hypertrophic gastropathy resembling Ménétrier's disease (11). Moreover, deletion of the $\beta$ subunit causes severe alteration of the structure of secretory canaliculi in parietal cells (12). To date, precise mechanisms of $\mathrm{H} 2 \mathrm{R}$ signals modulating secretory membrane transport in parietal cells remain unclear.

All cell lineages in the oxyntic mucosa arise from multipotent gastric stem cells in the isthmus. Many growth factors have been implicated in a wide range of biological activities, including gastric mucosal cell growth and differentiation (13). For example, TGF- $\alpha$ and EGF can stimulate cell proliferation in the gastric mucosa through activation of MAP kinase after binding their common receptors (EGF-Rs). Several other factors, such as bFGF, VEGF, trefoil peptides, and prostaglandins, have been implicated in gastrointestinal regeneration, which is induced in case of injury. The trophic effect of gastrin for oxyntic mucosa has also been studied. Longterm administration of gastrin, histamine H2R antagonist, or proton pump inhibitor (PPI) increased plasma gastrin concentration and lead to hypertrophy of oxyntic mucosa, caused by increased numbers of mucosal cells (14-16). In addition, recent studies using genetically engineered mice deficient in gastrin or CCK-BR have demonstrated the importance of gastrin signal(s) as a trophic effect on oxyntic mucosa (17-20). These mice exhibited a remarkable atrophy of the oxyntic mucosa accompanied by decreased numbers of parietal cells, ECL cells, and chief cells.

Despite the recent advances in knowledge regarding the many factors affecting the growth and development of digestive tissues, the effect of histamine in growth and differentiation of oxyntic mucosal cells has not been well characterized. A recent study using a gastric adenocarcinoma cell line has revealed that H2R antagonists alone could directly enhance cell proliferation (21).

In the present study, we have generated H2R-deficient mice by gene targeting in order to investigate the physiological significance of H2R. Analysis of gastric physiology on acid secretion in the mutant mice showed compensation by cholinergic mechanisms. In addition, H2R-deficient mice exhibited hypertrophy in gastric mucosa, caused by increased numbers of parietal cells, ECL cells, and other types of gastric mucosal cells. Moreover, the parietal cells of these mice were remarkably small, and their canaliculi and tubulovesicles were significantly altered. Thus, the H2R-mediated signals play crucial roles in preservation of normal tissue structure in gastric mucosa as well as normal secretory membrane structure of parietal cells.

\section{Methods}

Construction of the $H 2 R$ targeting vector and generation of mutant mice. An 18-kb EcoRI DNA fragment containing $1.2 \mathrm{~kb}$ of the entire coding region of $H 2 R$ (a single exon) was isolated from a mouse E14 ES cell genomic DNA library, as described previously (22), and used for construction of the targeting vector. A 6-kb XbaI fragment and a $0.7-\mathrm{kb}$ HindIII-NcoI fragment were used as the 5' long arm and 3' short arm, respectively. These arms were inserted on either side of PGK-neo cassette in PPNT vector containing a neomycin resistance gene $\left(n e o^{r}\right)$ as well as a herpes simplex virus-thymidine kinase gene ( $b s v$-tk) (Figure 1a). The targeting vector was designed to delete most of the coding region, including the translation start site.

E14 ES cells were transfected with the linearized targeting vector and selected with G418 and ganciclovir. Targeted ES clones were identified by PCR screening with primers H2R-R1 (5'-ACTGCACTCTTCTTACCCAG-3') and PGK1-R1 (5'-ACTTGTGTAGCGCCAAGTGC-3') and verified by genomic Southern analysis using a $3^{\prime}$ external probe (Figure 1, a and b). Two clones were microinjected into C57BL/6J blastocysts, yielding chimeric mice that transmitted the targeted mutation through the germ line. Male chimeras were crossed with female C57BL/6J mice to generate heterozygous mice. Mice used in experiments were obtained by intercrossing heterozygotes. The mice were maintained in the animal facility under specific pathogen-free (SPF) conditions with proper aeration, light, and temperature.

$R T-P C R$ analysis. For the analysis of $H 2 R$ gene expression, RT-PCR analysis was done using the stomach and brain from wild-type, heterozygous, and homozygous mice. The total RNAs were prepared from the stomach and brain according to a standard procedure. RT-PCR was performed with primers H2R-1 (5'-GGA ACA GCA GAA ATG GGA CC-3') and H2R-2 (5'-TGT TCT CTG ATG GTG GCT GC-3'), as described previously (22).

Measurement of gastric acid secretion. To evaluate the effect of antagonists on acid secretion, mice 12-16 weeks old were fasted overnight with free access to water. Saline, famotidine $(10 \mu \mathrm{g} / \mathrm{g}$ body wt; Sigma Chemical Co., St. Louis, Missouri, USA), or telenzepine $(10 \mu \mathrm{g} / \mathrm{g}$ body wt; Research Biochemicals International, Natick, Massachusetts, USA) was injected intravenously. The stomach was removed 1 hour later. Approximately $50 \mu \mathrm{L}$ of gastric juice was collected, and the $\mathrm{pH}$ was directly measured by using a $\mathrm{pH}$ meter (model D-21S; Horiba Ltd., Kyoto, Japan) with flat probe (model 6261-10C; Horiba Ltd.).

To evaluate the effect of stimulants on acid secretion, mice were fasted overnight with free access to water and anesthetized with ether for the epigastric laparotomy. PBS, histamine $(10 \mu \mathrm{g} / \mathrm{g}$ body wt; Sigma Chemical Co.), carbachol (1 $\mu \mathrm{g} /$ mouse, two times with 45-minute intervals; Sigma Chemical Co.), or rat gastrin-17 (1 $\mu \mathrm{g} / \mathrm{g}$ body wt; Sigma Chemical Co.) was injected subcutaneously after ligating the pylorus. The stomach was removed 1.5 hours later to collect the gastric juice. 
The acid output was determined by the volume of gastric juice, and $0.01 \mathrm{~N} \mathrm{NaOH}$ used for titration of the gastric juice adjusted up to $\mathrm{pH}$ 7.0.

Measurement of serum gastrin levels. Blood samples collected from 12-to 18-week-old mice were centrifuged at $6,000 \mathrm{~g}$ for 15 minutes to obtain the serum, which was then frozen at $-80^{\circ} \mathrm{C}$ until determination of the gastrin levels. The gastrin concentration was determined by means of ${ }^{125}$ I radioimmunoassay (Gastrin-RIA kit; Dainabot, Tokyo, Japan); the results are expressed as picograms of gastrin per milliliter of serum.

Measurement of stomach histamine. Each sample for histamine concentration was collected from the stomach according to the procedure described by Larsson (14). Briefly, the stomachs from 12-week-old mice were rinsed with PBS containing $10^{-6} \mathrm{M}$ semicarbazide hydrochloride, weighed, and homogenized in $0.01 \mathrm{M}$ sodium phosphate buffer. The homogenate was diluted 1:10 with phosphate buffer and heated in boiling water for 10 minutes to release bound histamine. The homogenate was then centrifuged at 3,300 $\mathrm{g}$ for 20 minutes, and the supernatant was used as the sample. The quantitative determination of histamine level in the sample was performed with Histamine Enzyme Immunoassay Kit (Immunotech, Marseilles, France).

Immunohistochemical detection of the BrdU incorporation. To evaluate the 5-bromo-2'-deoxyuridine (BrdU) incorporation in mucosal cells, mice were injected with 50 $\mathrm{mg} / \mathrm{kg}$ BrdU (Sigma Chemical Co.) intraperitoneally 1 hour before collecting the tissue samples, as described previously (23). Immunohistochemical detection of the BrdU incorporation was then performed using a murine $\mathrm{mAb}$ against BrdU (DAKO, Copenhagen, Denmark), which can identify single-stranded DNA.

The stomach was removed from mice treated with BrdU and opened along the greater curvature. The stomach samples were gently rinsed with PBS, fixed with Carnoy's fixative overnight, embedded in paraffin wax, and then sectioned at $4 \mu \mathrm{m}$. After deparaffinization and rehydration, slides were immersed in $1 \%$ hydrogen peroxide in methanol for 15 minutes for blocking of endogenous peroxidase activity and then equilibrated with PBS three times for 5 minutes. The slides were immersed in 1 $\mathrm{M} \mathrm{HCl}$ at $60^{\circ} \mathrm{C}$ for 8 minutes for denaturation of the tissue DNA, washed with PBS three times for 5 minutes, and incubated with $5 \%$ normal goat serum to block nonspecific binding of the primary antibody. The tissues were then incubated with the mAb to BrdU diluted to $1: 40$ in PBS for 2 hours. The slides were washed again in PBS and incubated with biotinylated anti-mouse $\operatorname{IgG}(1: 200$ in PBS) for 30 minutes. After further washings with PBS, the sections were incubated with peroxidase-conjugated streptavidin, washed with PBS, visualized by the diaminobenzidine tetrahydrochloride (DAB) reaction, and counterstained with hematoxylin.

Labeling index (LI) percentage was measured by counting the number of BrdU-positive cells and expressing the result as a percentage ratio of the total number of cells.
Immunohistochemical detection of parietal cells and ECL cells. The stomach samples were prepared in the same way as BrdU immunohistochemistry. Parietal cells and ECL cells were detected with a murine monoclonal anti- $\mathrm{H}^{+}, \mathrm{K}^{+}$-ATPase antibody (Medical \& Biological Laboratories Co., Nagoya, Japan) and a rabbit antibody against a peptide (359-389 amino acid) of rat chromogranin A (Yanaihara Institute Inc., Fujinomiya, Japan), respectively. Briefly, endogenous peroxidase activity was blocked by $1 \%$ hydrogen peroxide in methanol. Sections were incubated with primary antibody against

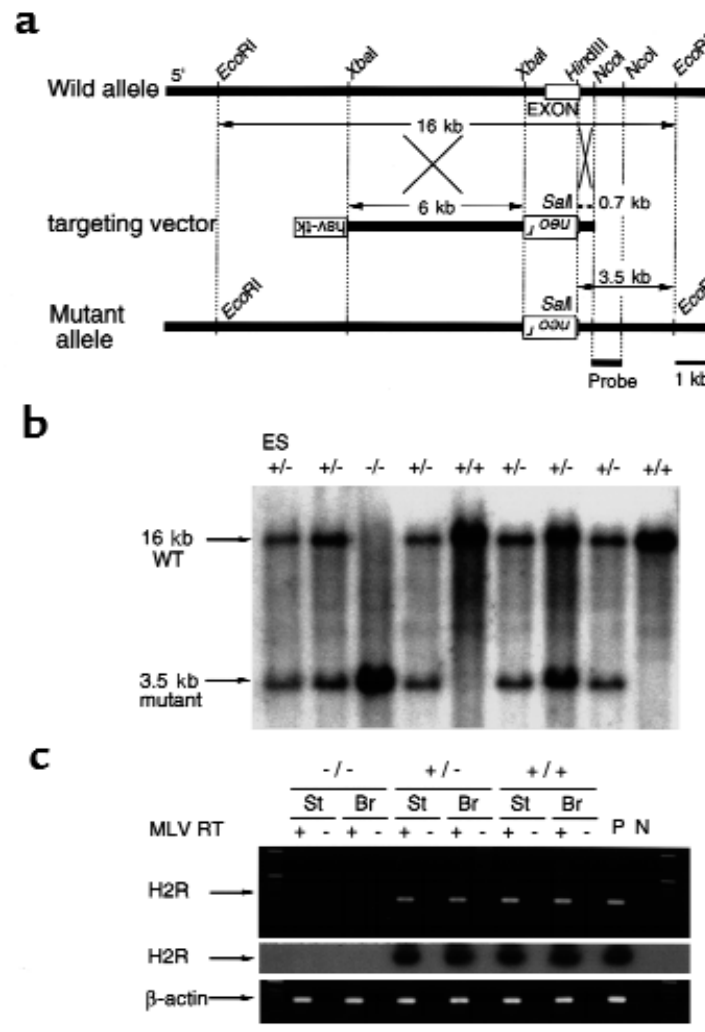

Figure 1

Targeted deletion of the mouse $H 2 R$ gene. (a) A diagram of the targeting vector (middle) designed to replace the Xbal-HindIII fragment containing the $H 2 R$ exon in the wild allele (top) with a pGK-neo cassette. The predicted mutant allele (bottom) generated by homologous recombination is also shown. A neomycin resistance gene $\left(n e o^{r}\right)$ and a herpes simplex virus-thymidine kinase gene ( $h s v-t k)$ inserted in reverse orientation are indicated as upside down. (b) Southern blot analysis of the homologous recombination. The genomic DNAs from a recombinant ES clone (left lane) and $F_{2}$ offspring obtained by a heterozygous intercrossing were digested with EcoRI and Sall and hybridized with the $3^{\prime}$ external probe. Each band corresponding to the wild-type allele $(16 \mathrm{~kb})$ and mutant allele $(3.5 \mathrm{~kb})$ is indicated. (c) The expression of $\mathrm{H} 2 \mathrm{R}$ mRNA in stomach ( $\mathrm{St}$ ) and brain ( $\mathrm{Br}$ ). Ethidium bromide staining of RT-PCR products corresponding to the $\mathrm{H} 2 \mathrm{R}$ (top) and endogenous $\beta$-actin (bottom). The cDNA was synthesized from DNasel-pretreated total RNA in the presence $(+)$ or absence $(-)$ of MLV reverse transcriptase (RT). RT-PCR products from the top panel were reconfirmed by Southern blot analysis using a genomic probe (middle). P, PCR products of $H 2 R$ genomic DNA and $\beta$ actin cDNA as a positive control; N, no template control for PCR. 


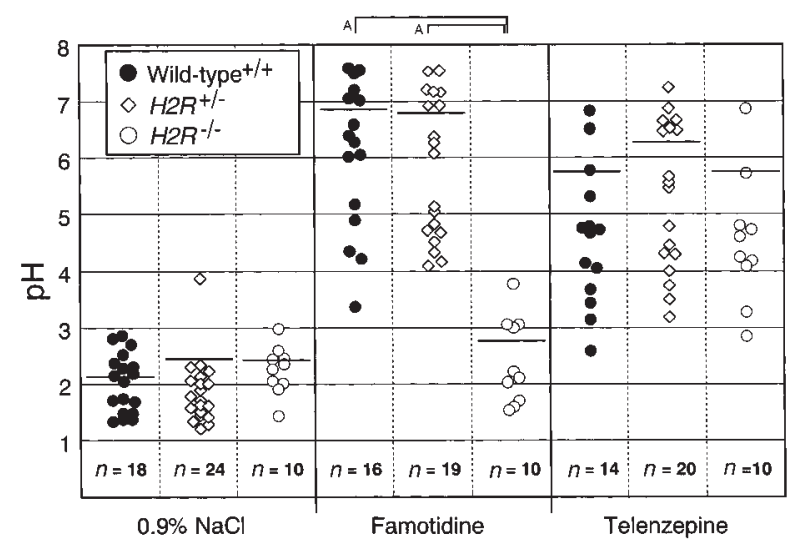

Figure 2

Basal- and pharmacological inhibited-gastric $\mathrm{pH}$ in $\mathrm{H} 2 \mathrm{R}$-deficient mice. Mice (12-16 weeks old) were fasted overnight, and $200 \mu \mathrm{L}$ $0.9 \% \mathrm{NaCl}$, an $\mathrm{H} 2 \mathrm{R}$ antagonist (famotidine; $10 \mu \mathrm{g} / \mathrm{g}$ body wt), or a muscarinic M1 receptor antagonist (telenzepine; $10 \mu \mathrm{g} / \mathrm{g}$ body $w t)$ was administered intravenously into each mouse. The gastric juice was collected 1 hour after intravenous injection. Each symbol (filled circles, wild-type; open diamonds, $\mathrm{H}_{2 R^{+/-}}$; open circles, $H 2 R^{-/-}$) represents the value corresponding to an individual animal. Bars, mean value. ${ }^{A} P<0.05$.

$\mathrm{H}^{+}, \mathrm{K}^{+}$-ATPase or chromogranin A (CgA) for 2 hours at room temperature. Sections were then incubated with biotinylated secondary antibodies followed by streptavidin peroxidase. Finally, slides were developed with $\mathrm{DAB}$ and counterstained with hematoxylin.

Electron microscopic analysis. The tissue samples were fixed with $3 \%$ glutaraldehyde buffered by $0.1 \mathrm{M}$ sodium cacodylate at $\mathrm{pH} 7.4$, washed with $0.1 \mathrm{M}$ sodium cacodylate buffer, and postfixed in $1 \%$ osmium tetroxide. After dehydration in graded alcohols and propylene oxide, tissue samples were embedded in Epon 812. Ultrathin sections were stained with uranyl acetate and lead citrate and examined with a JEOL 100CX electron microscope (JEOL Ltd., Tokyo, Japan).

Statistics. The statistical significance of difference was evaluated with Student's $t$ test. A $P$ value less than 0.05 was considered to be significant. The data are presented as means plus or minus SE.

\section{Results}

Histamine H2R-deficient mice are viable and fertile. Mice with a disrupted histamine $H 2 R$ gene was generated by gene targeting in mouse E14 ES cells (Figure 1a). Two independent $\mathrm{ES}$ clones successfully generated germline chimeras and their heterozygous mutant $\left(H 2 R^{+-}\right) \mathrm{F}_{1}$ mice. $\mathrm{H}_{2 \mathrm{R}^{+/-}}$mice were intercrossed to obtain homozygous mutants $\left(H 2 \mathrm{R}^{--}\right)$. The ratio of genotypes of the offspring did not deviate significantly from the expected 1:2:1 distribution of wild-type, $H 2 \mathrm{R}^{+/-}$and $H 2 \mathrm{R}^{-/-}$ offspring, respectively. Southern blot analysis of genomic DNA isolated from the targeted mice confirmed the structure of the gene deletion (Figure 1b). The absence of $H 2 R$ transcripts in $H 2 R^{-/-}$mice was confirmed by RT-PCR analysis using stomach and brain
RNA samples (Figure 1c). $H 2 R^{-/-}$mice developed without obvious abnormalities in their general appearance and grew with normal weight gain in comparison with wild-type littermates (Figure 4a). Both male and female $\mathrm{H} 2 \mathrm{R}^{-/-}$mice were fertile. Thus, the H2R deficiency did not impair embryogenesis or gametogenesis.

Basal gastric pH in H2R-deficient mice is normal. Because H2R blockade by selective H2R antagonists has been recognized to elevate gastric $\mathrm{pH}$, the basal gastric $\mathrm{pH}$ in $H 2 R^{-/-}$mice was measured. Contrary to our expectation, basal gastric $\mathrm{pH}$ in $\mathrm{H}_{2} \mathrm{R}^{-/-}$mice was normal and less than 3.0 (Figure 2). However, elevation of gastric $\mathrm{pH}$ by administration of a selective $\mathrm{H} 2 \mathrm{R}$ antagonist, famotidine, was not observed in $H 2 \mathrm{R}^{-/-}$mice, even though a significant inhibition of gastric acid secretion occurred in the stomach of $\mathrm{H}_{2} \mathrm{R}^{+/-}$and wild-type littermates. This indicates that the H2R is functionally disrupted in the null mutant mice. In contrast, a selective M1R antagonist, telenzepine, blocked the secretion of gastric acid in $H 2 \mathrm{R}^{-/}$mice as well as $H 2 \mathrm{R}^{+/-}$and wild-type littermates. These results suggest that gastric $\mathrm{pH}$ may be normally maintained in the mutant mice by signal(s) other than H2R, such as a signal from the muscarinic receptors.

Gastric acid secretion in H2R-deficient mice is regulated by signal(s) from muscarinic receptors, but not from gastrin receptors. Contrary to H2R blockade by antagonists, basal gastric $\mathrm{pH}$ was normally controlled in the H2R-deficient mice. Acid output was then examined in $H 2 R^{-1-}$ mice by stimulation with histamine, carbachol, or gastrin-17.

Acid secretion was measured over a 90-minute period (Figure 3), and there was no apparent difference in basal acid output among three genotypes. The acid output induced by histamine was upregulated approximately fivefold in wild-type mice $(26.1 \pm 2.65 \mu \mathrm{Eq} / \mathrm{h})$ compared with the basal level $(5.56 \pm 0.74 \mu \mathrm{Eq} / \mathrm{h})$, whereas it was

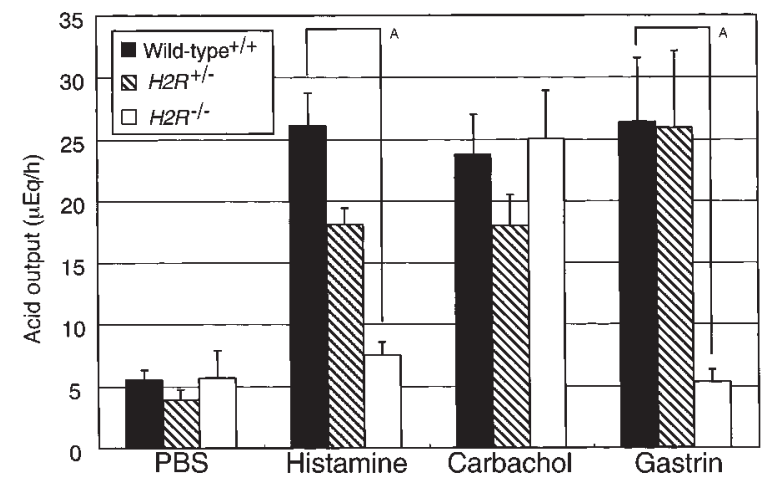

Figure 3

The regulation of gastric acid secretion depends on the muscarinic receptor signal in $\mathrm{H} 2 \mathrm{R}$-deficient mice. Wild-type mice (filled bars), $H 2 R^{+/-}$mice (hatched bars), and $H 2 R^{-1-}$ mice (open bars), 12-16 weeks old, received subcutaneous injection of histamine $(10 \mu \mathrm{g} / \mathrm{g}$ body wt), carbachol ( $1 \mu \mathrm{g} /$ mouse, two times), or gastrin-17 ( $1 \mu \mathrm{g} / \mathrm{g}$ body wt) after pylorus ligation. After 1.5 hours, the gastric juice was collected. The acid output was calculated as described in Methods. Results are expressed as means $\pm \mathrm{SE}$ of more than seven mice. ${ }^{A} P<0.005$. 

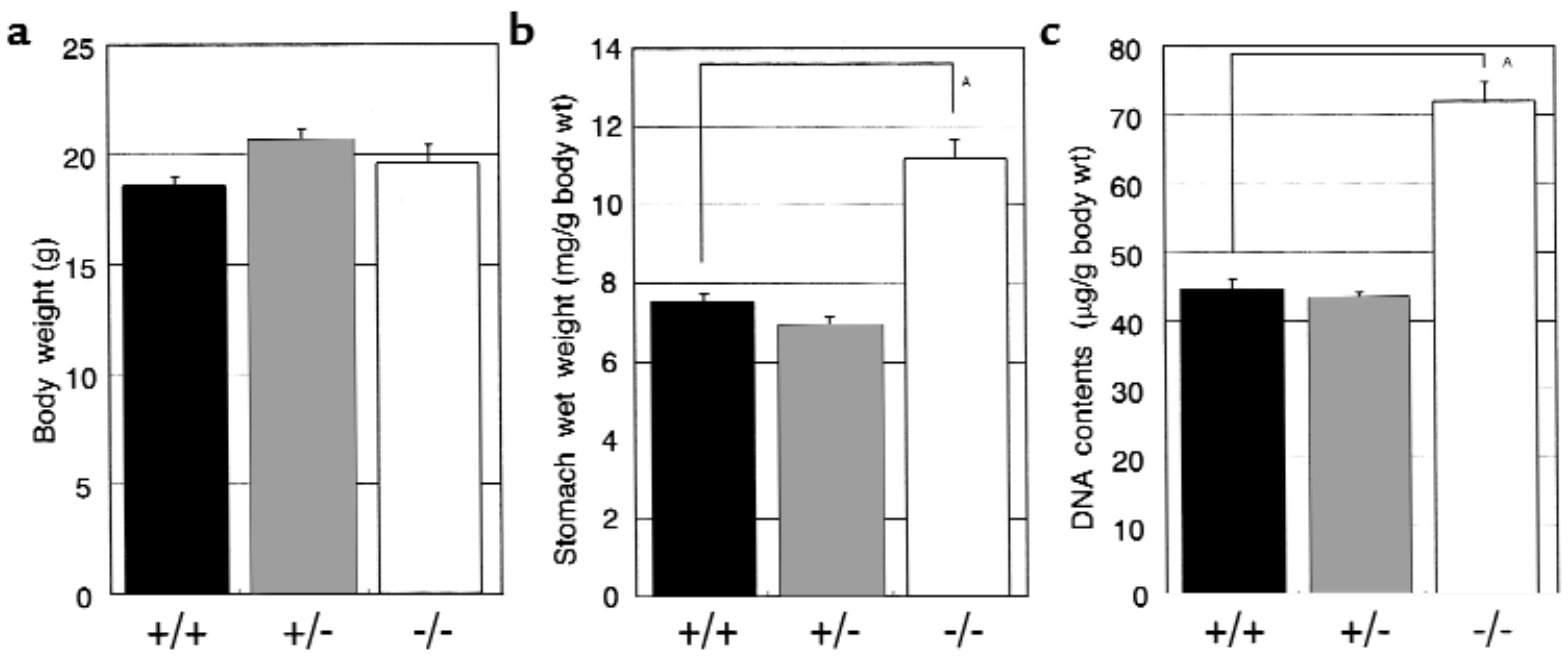

\section{Figure 4}

Increased wet weight and DNA contents of the stomach in H2R-deficient mice. Body weight (a), stomach wet weight (mg/g body wt) (b), and stomach DNA contents ( $\mu \mathrm{g} / \mathrm{g}$ body wt) (c) in 14-week-old female mice were measured. High molecular DNAs were extracted from the stomach of each mouse, and the DNA contents were measured spectrophotometrically at OD 260 . Results are expressed as means \pm SE of more than 10 mice. ${ }^{A} P<0.001$.

not increased in $H 2 R^{-/-}$mice $(7.52 \pm 1.02 \mu \mathrm{Eq} / \mathrm{h})$. These results reconfirmed the complete absence of a functional H2R in the null mutant mice. In contrast, acid output induced by carbachol was increased in $\mathrm{H}_{2} \mathrm{R}^{-/-}$ mice $(25.1 \pm 3.83 \mu \mathrm{Eq} / \mathrm{h})$ similar to that of wild-type mice $(23.8 \pm 3.23 \mu \mathrm{Eq} / \mathrm{h})$. Surprisingly, there was no response to stimulation with gastrin in $\mathrm{H}_{2} \mathrm{R}^{-/-}$mice $(5.31 \pm 1.00 \mu \mathrm{Eq} / \mathrm{h})$, even though marked elevation of the acid secretion was observed in $\mathrm{H}^{2 \mathrm{R}^{+/-}}(25.9 \pm 6.26$ $\mu \mathrm{Eq} / \mathrm{h})$ and wild-type $(26.4 \pm 5.22 \mu \mathrm{Eq} / \mathrm{h})$ littermates. These results strongly suggest that the muscarinic but not the gastrin-induced signal could compensate the $\mathrm{H} 2 \mathrm{R}$ signal for gastric acid production and also that an effect of gastrin on acid secretion is mainly mediated by $\mathrm{H} 2 \mathrm{R}$ upon stimulation with histamine released from ECL cells that express CCK-BR.

Hypergastrinemia and bypertrophy of gastric mucosa in $H 2 R$-deficient mice. It has been observed that treatment with antiulcer agents such as H2R antagonists and PPIs induced hypergastrinemia and hypertrophy of the gastric mucosa in rodents $(14,16)$. In the present study, serum gastrin levels, wet weights, and DNA contents of the stomach were assessed in $H 2 \mathrm{R}^{-/-}$mice.

The mean of serum gastrin level in 12- to 18-week-old $H 2 \mathrm{R}^{-/-}$mice was significantly elevated in comparison with that of wild-type mice $(1,528 \pm 243 \mathrm{pg} / \mathrm{mL}$ vs. 384 $\pm 42.3 \mathrm{pg} / \mathrm{mL} ; P<0.001)$.

To quantify the hypertrophy, wet weights and DNA contents of the stomach in 14-week-old female mice were measured. The mean wet weight in $H 2 R^{-/-}$mice $(11.19 \pm 0.47 \mathrm{mg} / \mathrm{g}$ body weight) was higher than that of wild-type control $(7.56 \pm 0.22 \mathrm{mg} / \mathrm{g}$ body wt) (Figure

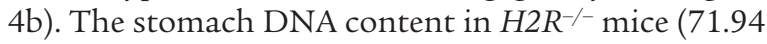
$\pm 2.74 \mu \mathrm{g} / \mathrm{g}$ body wt) was also significantly higher than that of wild-type controls $(44.49 \pm 1.53 \mu \mathrm{g} / \mathrm{g}$ body wt) (Figure 4c). These data indicate that the increased stomach wet weight in the mutant mice resulted from the increased numbers of the cells rather than increased volume of each cell in the stomach. Therefore, genetic ablation of $\mathrm{H} 2 \mathrm{R}$ leads to hypergastrinemia and hypertrophy of the gastric mucosa, similar to the rodent model treated with antiulcer agents.

Increased numbers of parietal and ECL cells in H2R-deficient mice. To further characterize the hypertrophy of the gastric mucosa, histological analysis was performed. There was no apparent difference between $\mathrm{H}_{2} \mathrm{R}^{-/-}$and wildtype mice in the nonglandular area in the fundus or pylorus region (antral mucosa; data not shown). However, the thickness of oxyntic mucosa in the glandular region was remarkably increased in 16-week-old $H 2 \mathrm{R}^{-/-}$ mice compared with wild-type mice (Figure 5). The hypertrophic change resulted in a formation of enlarged gastric folds in the glandular region (Figure 5a). The change in mucosal thickness was most prominent in the isthmus and neck region. In contrast, no remarkable changes were found in the pit region (Figure 5b).

To identify the predominant cell types that are increased in the hypertrophic mucosa, immunohistochemical analysis of parietal and ECL cell populations was undertaken. $\mathrm{H}^{+}, \mathrm{K}^{+}$-ATPase and $\mathrm{CgA}$ were used as markers to identify parietal cells and ECL cells, respectively. As shown in Figure 5, parietal cells were located throughout the hypertrophic oxyntic mucosa with increased cell numbers in $H 2 \mathrm{R}^{-/-}$mice. In addition, $\mathrm{H}^{+}, \mathrm{K}^{+}$-ATPase negative cells localized among parietal cells were increased in the isthmus and neck region (Figure 6, a and b). ECL cells in $H 2 R^{-/-}$mice were found not only in the basal region, but also in the neck region and isthmus with a marked increase in density, whereas those in wild-type mice were preferentially observed in the basal region (Figure 6, c and d). Indeed, histamine contents in the gastric mucosa were significantly 


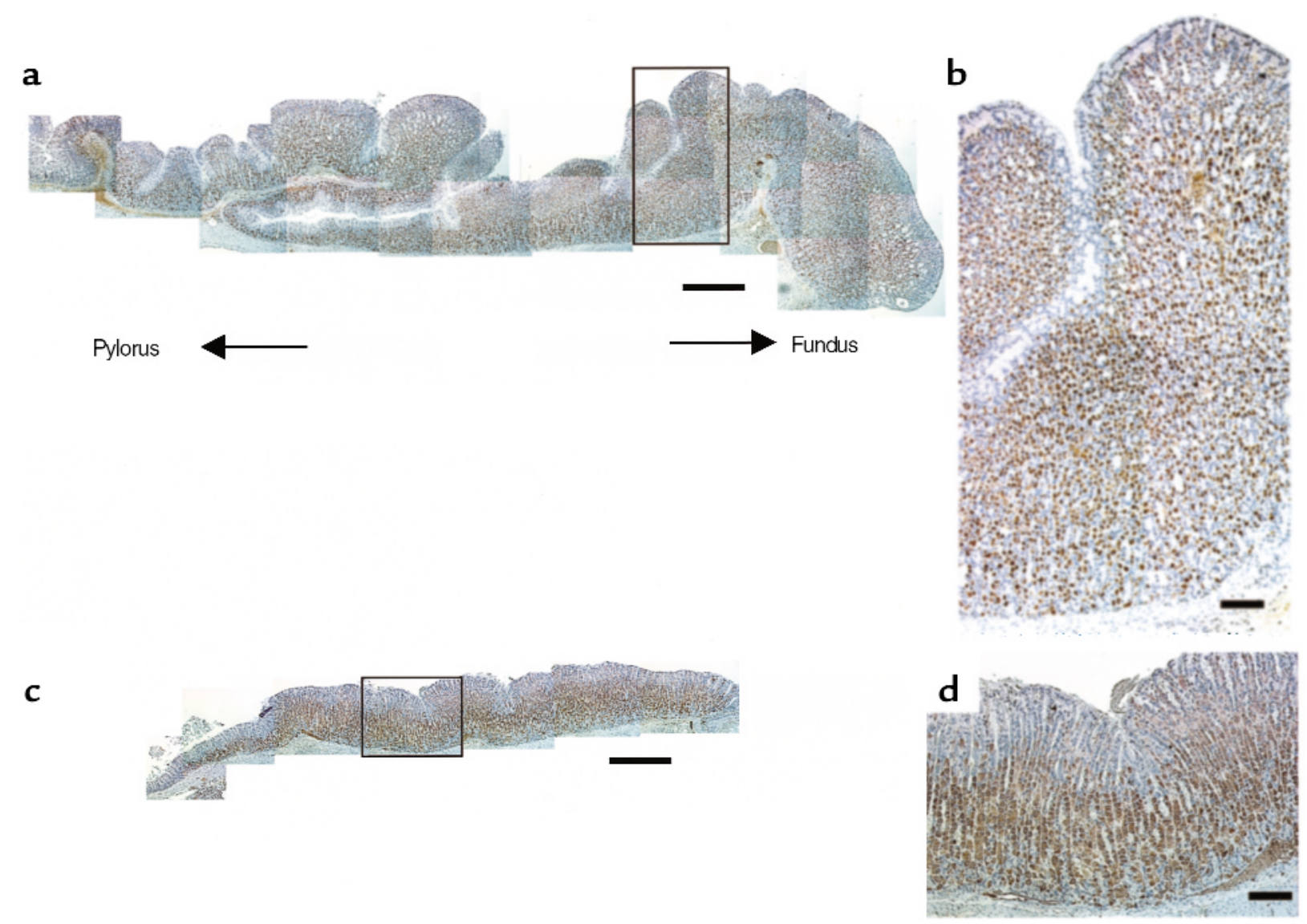

\section{Figure 5}

Hypertrophy of oxyntic mucosa in H2R-deficient mice. Comparison of the gross aspects of the glandular area in the corpus region immunostained with anti- $\mathrm{H}^{+}, \mathrm{K}^{+}$-ATPase antibody (specific for parietal cell) of a 16 -week-old $\mathrm{H} 2 \mathrm{R}^{-/-}$mouse (a and $\mathbf{b}$ ) and a wild-type mouse (c and d). Whole aspects of corpus region ( $\mathbf{a}$ and $\mathbf{c}$ ) and higher magnifications of areas boxed (b and $\mathbf{d}$ ) are shown. Sections were cut $4 \mu \mathrm{m}$ thick along the greater curvature. The thickness of oxyntic mucosa was remarkably increased in $\mathrm{H}_{2} \mathrm{R}^{-/-}$mice with formation of enlarged gastric folds. The change in mucosal thickness was the most prominent in the isthmus and neck region. Note that $\mathrm{H}^{+}, \mathrm{K}^{+}$-ATPase-positive parietal cells (brown) were located throughout the hypertrophic oxyntic mucosa with increased numbers of the cells in $H 2 R^{-1-}$ mice. (a and $\mathbf{c}$, bar $=$ $0.5 \mathrm{~mm} ; \mathbf{b}$ and $\mathbf{d}$, bar $=100 \mu \mathrm{m}$.)

$(P<0.05)$ elevated in $H 2 R^{-/-}$mice $(35,110 \pm 9,532 \mathrm{ng} / \mathrm{g}$ wet wt, $n=5)$ compared with that in wild-type mice $(8,124 \pm 978 \mathrm{ng} / \mathrm{g}$ wet $\mathrm{wt}, n=5)$. These findings suggest that the mucosal hypertrophy resulted from the increased numbers of parietal cells, ECL cells, and other $\mathrm{H}^{+}, \mathrm{K}^{+}$-ATPase negative cells.

To determine whether the increase in the numbers of parietal cells and ECL cells resulted from enhanced proliferation, BrdU incorporation in the oxyntic mucosa was examined. There was no difference in the BrdU incorporation in the hypertrophic oxyntic mucosa of 16-week-old $H 2 R^{-/-}$mice compared with age-matched wild-type mice (data not shown). However, the BrdU incorporation in the oxyntic mucosa was significantly increased in young 4-week-old $H 2 R^{-/-}$mice whose oxyntic mucosa did not yet exhibit the hypertrophy (Figure 6, e and f). Indeed, BrdU LI in the gastric mucosa was significantly elevated $(P<$ $0.001)$ in $H 2 R^{-/-}$mice $(9.48 \pm 0.20 \%, n=5)$ compared with that in wild-type mice $(4.08 \pm 0.20 \%, n=6)$. Thus the multipotent gastric stem cells in the isthmus are highly proliferative in $H 2 R^{-/-}$mice during the period before hypertrophy.

Morphological alteration of parietal cells in H2R-deficient mice. The morphological characteristics of parietal cells, normally identified by their large size and clear or acidophilic cytoplasm, were significantly altered in H2Rdeficient mice. The size of $\mathrm{H}^{+}, \mathrm{K}^{+}$-ATPase-positive parietal cells in 16-week-old $\mathrm{H}_{2 \mathrm{R}^{-/-}}$mice was significantly smaller than that of wild-type mice (Figure 6, a and b). This morphological alteration was already observed in 4-week-old young mutant mice whose gastric mucosal thickness was within a normal range of wild-type mice (data not shown).

The ultrastructure of the parietal cells in $\mathrm{H}_{2} \mathrm{R}^{-/-}$mice was quite distinct from that of wild-type mice (Figure 7). In normal parietal cells, secretory canaliculi with numerous microvilli were readily observed using electron microscopy (Figure 7a). The mitochondria were very prominent and scattered throughout the cytoplasm, and tubulovesicles were located mainly in the region close to the canaliculi. By contrast, the cyto- 
plasmic volume was remarkably reduced in the parietal cells of $\mathrm{H}_{2 \mathrm{R}^{-/-}}$mice, although the numbers of mitochondria in parietal cells appeared to be comparable to those of normal parietal cells (Figure 7, b-d). Moreover, many parietal cells contained enlarged secretory canaliculi with a lower density of microvilli and few typical tubulovesicles in the cytoplasm. These findings suggest that H2R deficiency caused the abnormal microstructure of secretory membranes of parietal cells.

\section{Discussion}

In the present study, we clarified the physiological roles of H2R-mediated signals in the gastric mucosa by using H2R-deficient mice. The H2R null mutant mice exhibited rather unexpectedly normal basal gastric $\mathrm{pH}$, which is clearly distinct from the elevated gastric $\mathrm{pH}$ observed in conventional mice treated with $\mathrm{H} 2 \mathrm{R}$ antagonists. Stimulation of acid secretion by histamine, as well as inhibition of acid secretion by the H2R antagonist, famotidine, were completely abrogated in $\mathrm{H}_{2} \mathrm{R}^{--}$mice, indicating that the H2R-mediated signal for gastric acid secretion is functionally disrupted. By contrast, the M1R antagonist, telenzepine, could inhibit acid secretion, and carbachol normally induced acid secretion in $\mathrm{H} 2 \mathrm{R}^{-1-}$ mice. These results indicate that impairment of acid secretion due to the absence of H2R could be overcome by cholinergic signaling. This phenomenon leads us to speculate that chronic application of H2R antagonists may reduce their efficacy as inhibitors of acid secretion due to compensation with signals from muscarinic receptors. Gastrin, on the other hand, was unable to evoke acid secretion in the mutant mice, suggesting that the mode of action of gastrin for acid secretion depends on H2R-mediated signaling.

Acid secretion by histamine depends on direct stimulation of H2R expressed on parietal cells, whereas acid secretion by ACh or gastrin has been thought to occur

\section{Figure 6}

Immunohistochemical observation of gastric mucosa in H2R-deficient mice. Comparison of gastric mucosa from wild-type (a, $\mathbf{c}$, and $\mathbf{e}$ ) and $H 2 R^{-/-}(\mathbf{b}, \mathbf{d}$, and $\mathbf{f})$ mice. Parietal cells in 16-week-old mice were stained with anti- $\mathrm{H}^{+}, \mathrm{K}^{+}$-ATPase antibody (a and $\mathbf{b}$ ). ECL cells in 16-week-old mice were stained with anti-chromogranin A antibody (c and $\mathbf{d}$ ). Gastric mucosa from 4-week-old mice injected intraperitoneally with $\mathrm{BrdU}$ was stained with anti-BrdU antibody (e and $\mathbf{f}$ ) as described in Methods. BrdU LI in wild-type mice and $\mathrm{H}_{2} \mathrm{R}^{-/-}$mice were $4.08 \pm 0.20 \%$ $(n=6)$ and $9.48 \pm 0.20 \%(n=5)$, respectively. (a and b, bar $=50 \mu \mathrm{m} ; \mathbf{c}-\mathbf{f}$, bar $=100 \mu \mathrm{m}$.) either directly by activation of parietal cells or indirectly by triggering histamine release from ECL cells. There has been controversy concerning the relative significance of direct stimulation on parietal cells and indirect action through histamine release. The present results demonstrated that cholinergic signal(s) for acid secretion may act through both direct and indirect stimulation of parietal cells.

Soll and colleagues have demonstrated that each receptor for ACh, gastrin, and histamine is separately expressed on an isolated canine parietal cell and have provided evidence for postreceptor synergism $(6,7,24,25)$. A combination of signals induced by histamine and either ACh or gastrin synergistically evoked acid secretion, which was greater than the additive effect of each agent. In vivo studies in which H2R antagonists block the acid secretion evoked not only by histamine, but also by ACh or gastrin, also support the notion of synergism (26-28). The potentiation has been thought to reflect interaction of the intracellular signal transduction pathways including the histaminergic cAMP cascade and gastrinergic/cholinergic $\mathrm{Ca}^{2+}$-dependent pathway. In vitro studies have demonstrated that a certain level of cAMP in parietal cells may be required for an optimal secretory response to the $\mathrm{Ca}^{2+}$-dependent pathway $(8,9)$. Contrary to the above notion, the present

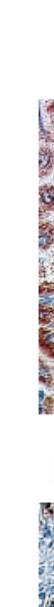
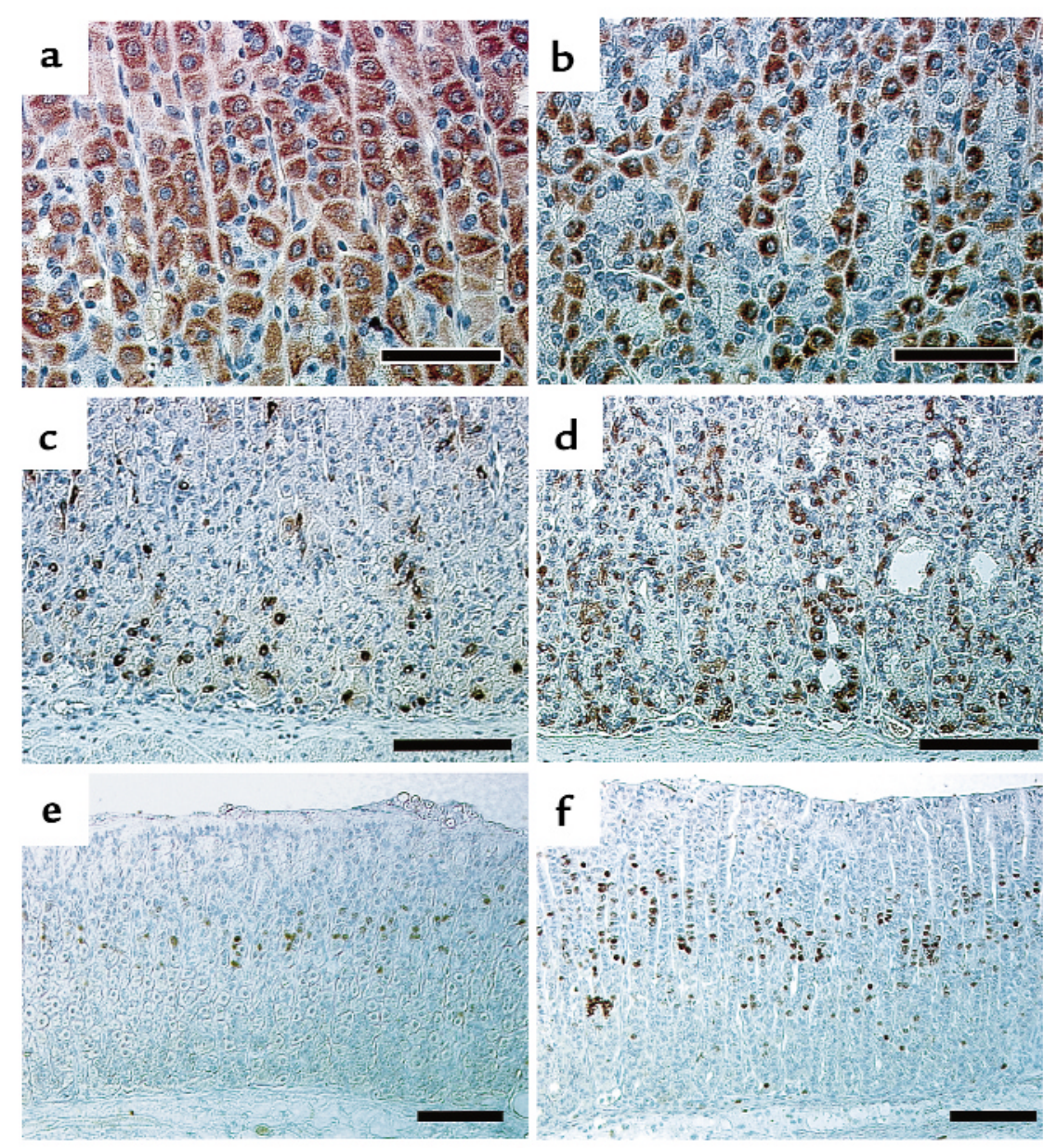
finding that cholinergic signaling could normally control the acid secretion in $\mathrm{H}_{2} \mathrm{R}^{-/-}$mice indicates that the $\mathrm{Ca}^{2+}$-dependent pathway alone can evoke acid secretion without potentiating the H2R-mediated cAMP pathway.

We observed that gastrin was unable to evoke acid secretion in $\mathrm{H}_{2} \mathrm{R}^{-/-}$mice but that ACh could. However, both M3R and CCK-BR signals are thought to share the same second messenger in parietal cells (2). Some differences between M3R and CCK-BR signaling have been reported previously. For example, activation of M3R by carbachol was unable to enhance cell proliferation of a human gastric cancer cell line, TMK-1, in which, however, DNA synthesis was augmented by gastrin, TGF- $\alpha$, and PMA (29). Muscarinic signaling could not rescue atrophy of oxyntic mucosa and hypochlorhydria in gastrin- or CCK-BR-deficient mice $(17-20)$. Moreover, our data indicated that the signal from muscarinic receptors for acid secretion is independent of H2R signaling, whereas that from gastrin receptors appears to be dependent on it. It seems, therefore, that distinct signaling pathways specific for gastrin signaling and cholinergic signaling may exist in parietal cells. Taken together with our present data, this leads us to propose that the muscarinic signal functions stimulate acid production, whereas the gastrin signal mainly functions to promote the proliferation of parietal cells. However, it has been reported that gastrin can directly stimulate isolated canine and porcine parietal cells on acid secretion (6-8). It is so far unclear why exogenously added gastrin could not induce acid secretion in the mutant mice. It might be due to the fact that the gastrin signal for acid secretion is completely dependent on H2R signaling or that gastrin receptors on the parietal cells may be maximally saturated by a high level of endogenous gastrin so that exogenous gastrin could not stimulate them. Further investigation of the effect of gastrin on acid secretion should be required.

In the present study, we observed hypergastrinemia in H2R-deficient mice. Chronic application of acidinhibitory drugs elevates serum gastrin levels $(14,16$, 30 ), and it has been suggested that the gastric $\mathrm{pH}$ influences the population of endocrine cells such as gastrinproducing G cells (30-32). The long-term elevation of gastric $\mathrm{pH}$ may increase G-cell density and then elevate serum gastrin levels. Contrary to the previous studies, H2R-deficient mice showed an increased serum gastrin level without elevation of basal gastric $\mathrm{pH}$. The mechanism of hypergastrinemia in $\mathrm{H} 2 \mathrm{R}$-deficient mice remains to be determined. However, we have demonstrated an absence of a gastrin-induced secretory response after exogenous gastrin treatment, which would predict that meal-induced acid secretion is severely impaired in the mutant mice.

Similar to the rodent model treated with $\mathrm{H} 2 \mathrm{R}$ antagonists (14), the H2R-deficient mice exhibited a marked hypertrophy of the gastric mucosa with an increase in numbers of parietal cells, ECL cells, and other types of
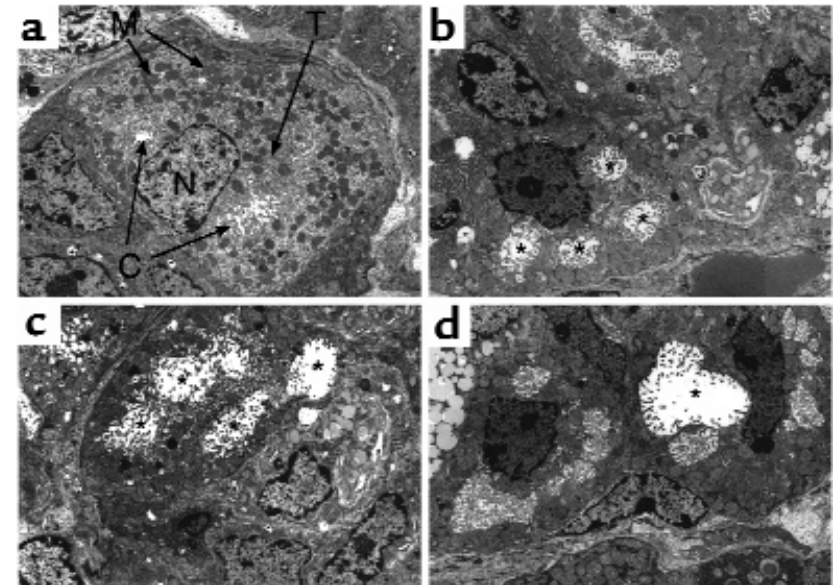

Figure 7

Ultrastructure of parietal cells in $\mathrm{H} 2 \mathrm{R}$-deficient mice. Electron microscopy of parietal cells from 18-week-old control (a) and $\mathrm{H} 2 \mathrm{R}^{-/-}$ (b, c, and d) mice. In parietal cells of control mice, typical secretory canaliculus $(C)$ with numerous microvilli and tubulovesicles $(T)$ were observed. In $\mathrm{H} 2 \mathrm{R}^{-/-}$mice, relatively small parietal cells contained enlarged secretory canaliculi $\left({ }^{*}\right)$ with a lower density of microvilli and few typical tubulovesicles in the cytoplasm. M, mitochondrion; $\mathrm{N}$, nucleus. $\times 4,000$.

cells. Because gastrin has a powerful trophic effect on oxyntic mucosal cells in vivo $(15-20,23)$ as well as in vitro $(33,34)$, it is probable that the elevated levels of serum gastrin contribute to the hypertrophy in H2Rdeficient mice. However, the study using a gastric adenocarcinoma cell line has revealed that $\mathrm{H} 2 \mathrm{R}$ antagonists, roxatidine and ranitidine, enhanced parietal cell proliferation without any increase in the amount of mRNA expression of either TGF- $\alpha$ or EGFR, indicating that the H2R-mediated signal may be involved in the gastric cell proliferation (21). Thus, the increased numbers of oxyntic mucosal cells in H2R-deficient mice may be, in part, a direct consequence of the deficiency of H2R-mediated signaling in addition to hypergastrinemia.

It is important to note that the morphological characteristics of the parietal cells were remarkably altered in H2R-deficient mice. The size of parietal cells in these mice was significantly smaller despite the increased numbers of cells. This morphological alteration was already observed in young mutant mice whose gastric mucosa was not yet hypertrophic. Thus the morphological change in parietal cells may reflect the direct effect of H2R deficiency rather than the indirect effect of hypertrophic change of the gastric mucosa. Electron microscopic observation of these abnormal parietal cells revealed structural alterations of the secretory membrane systems including secretory canaliculi and intracellular tubulovesicles. The abnormal parietal cells contained enlarged secretory canaliculi with a lower density of microvilli and few typical tubulovesicles. Secretory membrane transport is one of the critical mechanisms for regulation of acid secretion. The activation of acid secretion involves the exocytosis of $\mathrm{H}^{+}, \mathrm{K}^{+}$-ATPase to the cell surface by fusion of tubu- 
lovesicles with the apical membranes, whereas the cessation of acid secretion is associated with endocytosis of the $\mathrm{H}^{+}, \mathrm{K}^{+}$-ATPase and regeneration of tubulovesicles. Decreased numbers of tubulovesicles in H2R-deficient mice may be caused by impairment of generation or regeneration of tubulovesicles in the parietal cells. A recent study has revealed that a tyrosine-based motif in the $\beta$ subunit of $\mathrm{H}^{+}, \mathrm{K}^{+}$-ATPase is required for reinternalization of $\mathrm{H}^{+}, \mathrm{K}^{+}$-ATPase and regeneration of tubulovesicles. A mutation in the tyrosine-based motif of $\beta$ subunit causes hypertrophic gastropathy resembling Ménétrier's disease (11). The $\beta$ subunit-deficient mice also exhibit abnormal structure of the secretory canaliculi in parietal cells and hypertrophy of gastric mucosa (12). Interestingly, the gastric juice in the stomach with the gigantic folds of H2R-deficient mice was highly viscous and glossy (data not shown), which also resembles Ménétrier's disease. This is the first evidence that histamine signaling mediated by H2R may control the cellular size of parietal cells and preserve the normal structure of the secretory membrane in parietal cells. However, it is uncertain whether the morphological abnormality in the parietal cell is indeed functionally coupled to the potency of acid secretion.

In conclusion, the present study demonstrates the physiological significance of $\mathrm{H} 2 \mathrm{R}$ signaling involved in functional regulation of acid secretion as well as gastric architecture, including proliferation and attainment of normal secretory membrane structures of parietal cells. The H2R-deficient mouse provides an important tool for further understanding the molecular mechanisms for gastric function and morphological regulation of the oxyntic mucosa.

\section{Acknowledgments}

The authors express sincere thanks to Teruo Watanabe for his kind support in electron microscopic analysis, Katsuo Sueishi for valuable suggestions and providing us with the laboratory space necessary for histological studies, and to Peter Burrows for his helpful comments and review of the manuscript. We are also grateful to Sachiko Suematsu, Fusao Makishima, Naoko (Okuda) Tabeta, Ryosuke Suzuki, Beatrice Beguier, and Kae Kobayashi for their assistance.

1. Karam, S.M., and Leblond, C.P. 1992. Identifying and counting epithelial cell types in the "corpus" of the mouse stomach. Anat. Rec. 232:231-246.

2. Hersey, S.J., and Sachs, G. 1995. Gastric acid secretion. Physiol. Rev. 75:155-189.

3. Shamburek, R.D., and Schubert, M.L. 1993. Pharmacology of gastric acid inhibition. Baillieres Clin. Gastroenterol. 7:23-54.

4. Feldman, M., and Burton, M.E. 1990. Histamine2-receptor antagonists. Standard therapy for acid-peptic diseases (1). N. Engl. J. Med. 323:1672-1680

5. Feldman, M., and Burton, M.E. 1990. Histamine2-receptor antagonists. Standard therapy for acid-peptic diseases (2). N. Engl. J. Med. 323:1749-1755.

6. Soll, A.H. 1978. The interaction of histamine with gastrin and carbamylcholine on oxygen uptake by isolated mammalian parietal cells. $J$. Clin. Invest. 61:381-389.

7. Soll, A.H. 1982. Potentiating interactions of gastric stimulants on [14 C] aminopyrine accumulation by isolated canine parietal cells. Gastroenterology. 83:216-223.

8. Li, Z.Q., Cabero, J.L., and Mardh, S. 1995. Gastrin and carbachol require cAMP to elicit aminopyrine accumulation in isolated pig and rat parietal cells. Am. J. Physiol. 268:G82-G89.

9. Li, Z.Q., and Mardh, S. 1996. Interactions between Ca2+- and cAMPdependent stimulatory pathways in parietal cells. Biochim. Biophys. Acta. 1311:133-142.

10. Karam, S.M. 1993. Dynamics of epithelial cells in the corpus of the mouse stomach. IV. Bidirectional migration of parietal cells ending in their gradual degeneration and loss. Anat. Rec. 236:314-332.

11. Courtois-Coutry, N., et al. 1997. A tyrosine-based signal targets H/KATPase to a regulated compartment and is required for the cessation of gastric acid secretion. Cell. 90:501-510.

12. Scarff, K.L., Judd, L.M., Toh, B.H., Gleeson, P.A., and Van Driel, I.R. 1999. Gastric $\mathrm{H}^{+}, \mathrm{K}^{+}$-adenosine triphosphatase $\beta$ subunit is required for normal function, development, and membrane structure of mouse parietal cells. Gastroenterology. 117:605-618.

13. Jones, M.K., Tomikawa, M., Mohajer, B., and Tarnawski, A.S. 1999. Gastrointestinal mucosal regeneration: role of growth factors. Front. Biosci. 4:D303-D309.

14. Larsson, H., et al. 1986. Plasma gastrin and gastric enterochromaffinlike cell activation and proliferation. Studies with omeprazole and ranitidine in intact and antrectomized rats. Gastroenterology. 90:391-399.

15. Ryberg, B., Axelson, J., Hakanson, R., Sundler, F., and Mattsson, H. 1990. Trophic effects of continuous infusion of [Leu15]-gastrin-17 in the rat. Gastroenterology. 98:33-38.

16. Lee, H., Hakanson, R., Karlsson, A., Mattsson, H., and Sundler, F. 1992. Lansoprazole and omeprazole have similar effects on plasma gastrin levels, enterochromaffin-like cells, gastrin cells and somatostatin cells in the rat stomach. Digestion. 51:125-132.

17. Nagata, A., et al. 1996. G protein-coupled cholecystokinin-B/gastrin receptors are responsible for physiological cell growth of the stomach mucosa in vivo. Proc. Natl. Acad. Sci. USA. 93:11825-11830.

18. Koh, T.J., et al. 1997. Gastrin deficiency results in altered gastric differentiation and decreased colonic proliferation in mice. Gastroenterology. 113:1015-1025.

19. Langhans, N., et al. 1997. Abnormal gastric histology and decreased acid production in cholecystokinin-B/gastrin receptor-deficient mice. Gastroenterology. 112:280-286.

20. Friis-Hansen, L., et al. 1998. Impaired gastric acid secretion in gastrindeficient mice. Am. J. Physiol. 274:G561-G568.

21. Ciacci, C., et al. 1996. Histamine H2-receptor antagonists stimulate proliferation but not migration of human gastric mucosal cells in vitro. Dig. Dis. Sci. 41:972-978

22. Kobayashi, T., et al. 1996. Cloning, RNA expression, and chromosomal location of a mouse histamine H2 receptor gene. Genomics. 37:390-394.

23. Wang, T.C., et al. 1996. Processing and proliferative effects of human progastrin in transgenic mice. J. Clin. Invest. 98:1918-1929.

24. Soll, A.H. 1980. Secretagogue stimulation of $\left[{ }^{14} \mathrm{C}\right]$ aminopyrine accumulation by isolated canine parietal cells. Am. J. Physiol. 238:G366-G375.

25. Soll, A.H., Amirian, D.A., Thomas, L.P., Reedy, T.J., and Elashoff, J.D. 1984. Gastrin receptors on isolated canine parietal cells. J. Clin. Invest. 73:1434-1447.

26. Black, J.W., Duncan, W.A., Durant, C.J., Ganellin, C.R., and Parsons, E.M. 1972. Definition and antagonism of histamine H 2 -receptors. Nature. 236:385-390.

27. Grossman, M.I., and Konturek, S.J. 1974. Inhibition of acid secretion in dog by metiamide, a histamine antagonist acting on $\mathrm{H} 2$ receptors. Gastroenterology. 66:517-521.

28. Hirschowitz, B.I., and Molina, E. 1983. Effects of four H2 histamine antagonists on bethanechol-stimulated acid and pepsin secretion in the dog. J. Pharmacol. Exp. Ther. 224:341-345.

29. Kodaira, M., et al. 1999. Functional muscarinic m3 receptor expressed in gastric cancer cells stimulates tyrosine phosphorylation and MAP kinase. J. Gastroenterol. 34:163-171.

30. Arnold, R., Frank, M., Simon, B., Eissele, R., and Koop, H. 1992. Adaptation and renewal of the endocrine stomach. Scand. J. Gastroenterol. Suppl. 193:20-27.

31. Arnold, R., et al. 1982. Antral gastrin-producing G-cells and somatostatin-producing D-cells in different states of gastric acid secretion. Gut. 23:285-291.

32. Creutzfeldt, W., et al. 1986. Effect of short- and long-term feeding of omeprazole on rat gastric endocrine cells. Digestion. 35(Suppl. 1):84-97.

33. Ito, M., et al. 1993. Functional characterization of a human brain cholecystokinin-B receptor. A trophic effect of cholecystokinin and gastrin. $J$. Biol. Chem. 268:18300-18305.

34. Seva, C., Dickinson, C.J., and Yamada, T. 1994. Growth-promoting effects of glycine-extended progastrin. Science. 265:410-412. 